\title{
ANGEBOT UND NACHFRAGE
}

Liebe Leserin, lieber Leser,

„Window of opportunities“ - so werden im englischen Sprachgebrauch besondere Gelegenheiten bezeichnet, die sich aufgrund günstiger Randbedingungen ergeben. Der Großmotorenbereich erlebt dieses Fenster der Möglichkeiten derzeit bei Gasmotoren. Stark fallende Gaspreise sowie immer höherer Aufwand durch strenge Emissionsgesetzgebungen für Dieselmotoren machen den Gasantrieb extrem attraktiv. Als Konsequenz fragen die Anwender Gasmotoren immer stärker nach. Die Motorenhersteller reagieren mit massiver Aufstockung der Entwicklungskapazitäten und Ausbau ihrer Produktpalette, bis hin zu Gasmotoren für Schiffe und mobile Anwendungen.

Bei der Elektromobilität hingegen scheint das Fenster der Möglichkeiten auf längere Sicht verschlossen zu bleiben. Eingeschränkter Nutzwert und hohe Kosten machen Elektroautos gegenüber Fahrzeugen mit Verbrennungsmotor für die breite Endkundenschicht wenig interessant. Natürlich wird es Weiterentwicklungen geben, die den Antrieb in diesen Punkten verbessern. Allerdings sind die Möglichkeiten durch physikalische und chemische Grenzen vorgegeben, sodass die Fortschritte im Ergebnis vermutlich zu klein sein werden. So geht José Avila, Mitglied des Continental-Vorstands, im Interview auf Seite 20 zwar davon aus, dass sich die Batteriekosten bis 2020 halbieren werden, räumt aber auch ein, dass sie mit 350 Euro pro kWh auch dann noch sehr hoch bleiben. Hier stimmen die Randbedingungen für die Entwicklung kundengerechter Produkte nicht, was sich letztlich durch fehlende Marktnachfrage auswirkt. Um die Elektromobilität aus ihrem Schattendasein zu führen, haben einige europäische Länder großzügige staatliche Förderungen beim Kauf eines Elektrofahrzeugs eingeführt. Doch auch das bietet keine nachhaltige Lösung des Problems, weil die Zeit für die Elektromobilität offensichtlich noch nicht reif ist. Natürlich kann eine temporäre Förderung wichtige Marktimpulse geben. Bei der Elektromobilität müsste man den Absatz allerdings langfristig mit hohen Summen fördern, um eine künstliche Nachfrage zu generieren. Das hat mit einem gesunden Zusammenspiel aus Angebot und Nachfrage nichts mehr zu tun. Wie ist Ihre Meinung? Schreiben Sie mir doch per Mail an Richard.Backhaus@springer.com.

Herzlichst, Ihr

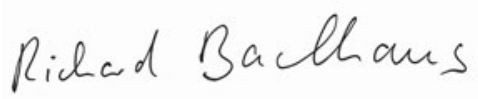

\section{RICHARD BACKHAUS,}

Stellvertretender Chefredakteur

Wiesbaden, 15. November 2012

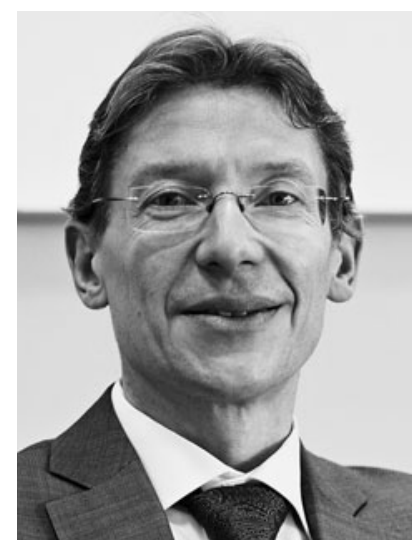

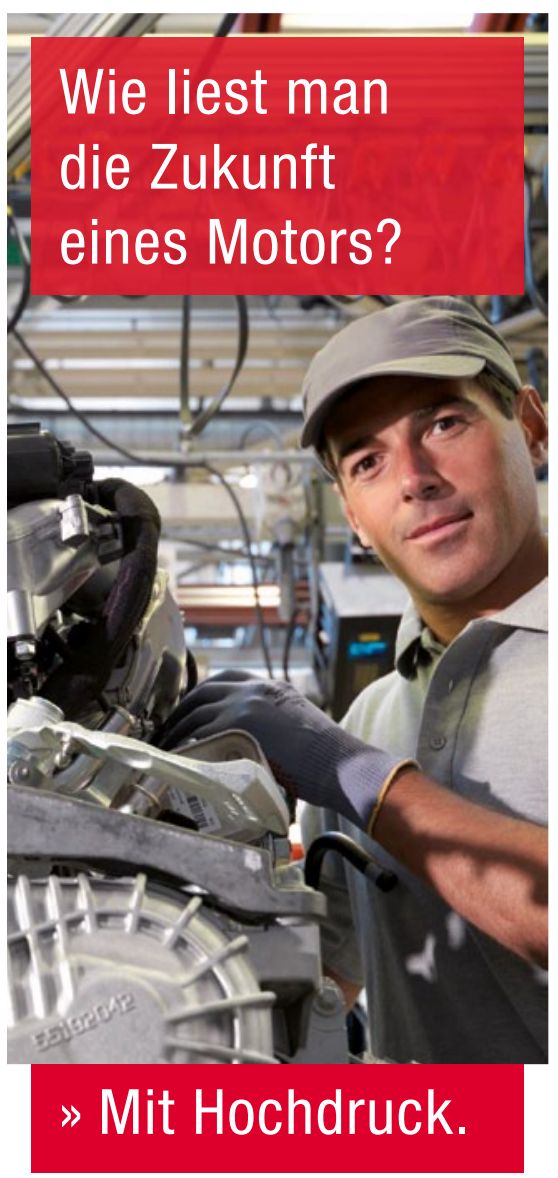

Impulsdruckprüfungen werden für die Ermittlung der Dauerfestigkeit von Komponenten der DieselEinspritztechnologie eingesetzt. Maximator Impulsdruckanlagen ebnen dadurch im Fahrzeugbau den Weg für Innovationen auf sicherer Basis. Darüber hinaus bieten wir Autoherstellern und Zulieferern maßgeschneiderte Prüfund Autofrettageanlagen. Nehmen Sie Kontakt auf oder besuchen Sie uns auf maximator.de

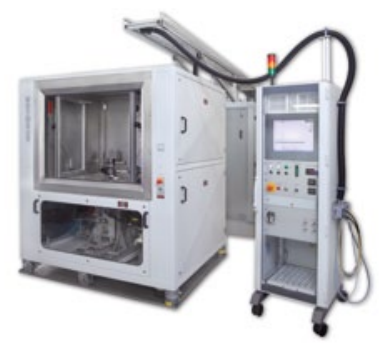

MAXIMATOR Maximum Pressure.

MAXIMATOR GmbH, Lange Straße 6, 99734 Nordhausen, Telefon +49 (0) 3631 9533-0, www.maximator.de 